\title{
Pharmacologically Distinct, Pertussis Toxin-Resistant Inward Currents Evoked by Metabotropic Glutamate Receptor (mGluR) Agonists in Dorsolateral Septal Nucleus (DLSN) Neurons
}

\author{
Fang Zheng and Joel P. Gallagher \\ Department of Pharmacology and Toxicology, University of Texas Medical Branch at Galveston, Galveston, Texas \\ $77555-1031$
}

We have reported previously that a selective metabotropic glutamate receptor (mGluR) agonist, $(1 S, 3 R)$-1-aminocyclopentane-1,3-dicarboxylic acid (1S,3R-ACPD), caused a slow membrane depolarization in rat dorsolateral septal nucleus (DLSN) neurons. Using single electrode voltage-clamp recording methods, we now investigate the pharmacological properties of the receptor that mediates ACPD-induced membrane currents in DLSN neurons recorded from pertussis toxin (PTX)-treated rats.

Two pharmacologically distinct inward currents, that is, the ACPD current and $Q_{m}$ current, have been identified based on their agonist preference and sensitivity to various antagonists. The ACPD current is blocked by L-2-amino-4-phosphonobutyric acid (L-AP4), but is insensitive to L-aspartic acid- $\beta$-hydroxamate (L-AA $\beta H$ ), (+)- $\alpha$-methyl-4-carboxyphenylglycine (+)-MCPG), or L-2-amino-3-phosphonopropionic acid (L-AP3). The $Q_{m}$ current is blocked by L-AA $\beta H$ and (+)-MCPG, but is insensitive to L-AP3 or L-AP4. These two inward currents distribute differentially within subpopulations of DLSN neurons. The ACPD current is the only current observed in most DLSN "burster" neurons, while the $Q_{m}$ current is observed more frequently in DLSN "nonburster" neurons. The pharmacological profiles of these currents suggest that the $Q_{m}$ current is likely mediated by mGluR 1 or mGluR5, while the ACPD current is mediated by receptors that are pharmacologically distinct from any of the currently cloned mGluRs.

[Key words: metabotropic glutamate receptor, inward current, pertussis toxin, pharmacology, 1S,3R-ACPD, quisqualate, dorsolateral septum]

Metabotropic glutamate receptors (mGluRs) are receptors coupled to various second-messenger systems (Nakanishi, 1992; Schoepp and Conn, 1993), and so far, seven members of the mGluR family have been cloned. Contrary to the rapid growth of information gained with a molccular biology approach, studies about the functional roles of mGluRs have been hindered by the confusion and contradiction in the field of mGluR pharmacology. The current pharmacological knowledge about this new family of glutamate receptors is primarily based on bio-

\footnotetext{
Received Mar. 31, 1994; revised June 23, 1994; accepted July 13, 1994.

This work is supported by NIMH Grant MH 39163.

Correspondence should be addressed to Dr. Joel P. Gallagher at the above address.

Copyright (C) 1995 Society for Neuroscience $0270-6474 / 95 / 150504-07 \$ 05.00 / 0$
}

chemical studies in various whole brain tissues or cell cultures, or studies of cloned receptors in an artificial expression system. Coexistence of multiple mGluRs in most brain areas (Table 1, Gallagher et al., 1994a) results in ambiguous pharmacological data from most biochemical studies. Thus, complete pharmacological data of a native mGluR from rat CNS neurons in an adult animal is still unavailable.

The rat dorsolateral septal nucleus (DLSN), an important limbic relay nucleus, possesses the highest density of metabotropic glutamate receptor-like binding sites in adult rats (Cha et al., 1990). We have demonstrated that trans-( \pm )-1-amino1,3-cyclopentanedicarboxylic acid (t-ACPD), a selective metabotropic glutamate agonist, induced several electrophysiological responses: (1) membrane potential changes, (2) burst firing, and (3) enhancement of a slow afterdepolarizing potential (sADP). Among these responses, only burst firing induced by $1 S, 3 R$ ACPD was blocked by pertussis toxin (PTX) (Zheng and Gallagher, 1993), suggesting that multiple mGluRs exist in rat DLSN neurons. In the present study, we investigate the pharmacological properties of those PTX-resistant mGluRs responsible for ACPD-induced membrane currents. Based on the rank order of agonist potency and the sensitivity to various putative antagonists, we concluded that multiple subtypes of receptors are responsible for ACPD-induced inward currents in rat DLSN neurons. One subtype of mGluRs in the rat DLSN resembles the cloned PLC-coupled mGluRs, that is, mGluR1 and mGluR5. The remaining subtype is distinct pharmacologically from any cloned subtypes of mGluRs.

\section{Materials and Methods}

Pertussis toxin injection. Male Sprague-Dawley rats (100-150 gm) were used. Each animal was anesthetized by intraperitoneal injection of an anesthetic consisting of pentobarbital $(0.972 \mathrm{ml}, 50 \mathrm{mg} / \mathrm{ml})$, chloral hydrate $(0.212 \mathrm{~g})$, propylene glycol $(2.0 \mathrm{ml})$, ethanol $(0.5 \mathrm{ml})$, and $\mathrm{MgSO}_{4}$ $(0.106 \mathrm{~g})$ in $5 \mathrm{ml}$ total volume. Animals received stereotaxic injections of pertussis toxin $(0.5 \mu \mathrm{g} / \mu \mathrm{l}, 5.0 \mu \mathrm{l})$ into the ipsilateral lateral ventricle and were then allowed to survive 3-5 d before being sacrificed (Thalmann, 1987; Twery et al., 1991). The exact placement of the intracerebroventricular injection was visually verified in each animal when the coronal slices were made.

Brain slice preparations. Rat forebrain coronal slices containing septal nuclei were obtained in a manner described previously (Stevens et al., 1984). In brief, male Sprague-Dawley rats were sacrificed by decapitation. Coronal slices (500 $\mu \mathrm{m}$ thick) were cut and maintained submerged in a bath chamber at $32^{\circ} \mathrm{C}$. The bath solution contained (in mM) $\mathrm{NaCl}, 117 ; \mathrm{KCl}, 4.7 ; \mathrm{MgCl}_{2}, 1.2 ; \mathrm{CaCl}_{2}, 2.5 ; \mathrm{NaH}_{2} \mathrm{PO}_{4}, 1.2 ; \mathrm{NaHCO}_{3}$, 25; D-glucose, 10 ; bubbled with $95 \% \mathrm{O}_{2}-5 \% \mathrm{CO}_{2}$ to maintain pH at 7.4. Standard intracellular current-clamp recording and single electrode voltage-clamp recording. Both standard intracellular current-clamp and 
A

$100 \mu \mathrm{M}$ 1S,3R-ACPD

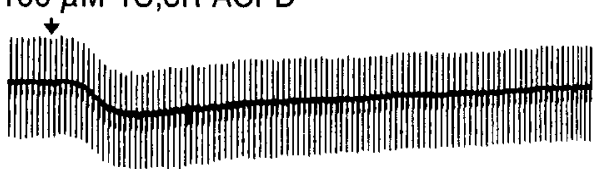

$\mid \begin{aligned} & 200 \mathrm{pA} \\ & 20 \mathrm{sec}\end{aligned}$

B

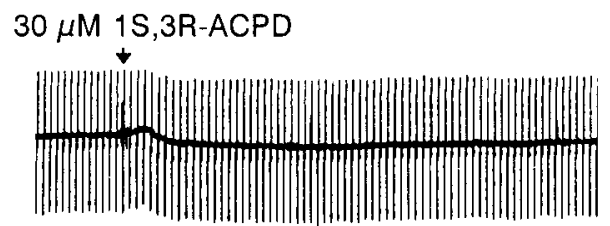

$V_{h}=-70 \mathrm{mV}$

$30 \mu \mathrm{M}$ 1S,3R-ACPD

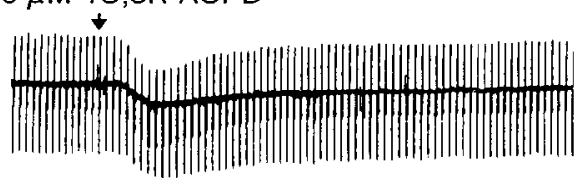

$V_{h}=-80 \mathrm{mV}$

$200 \mathrm{pA}$

$20 \mathrm{sec}$

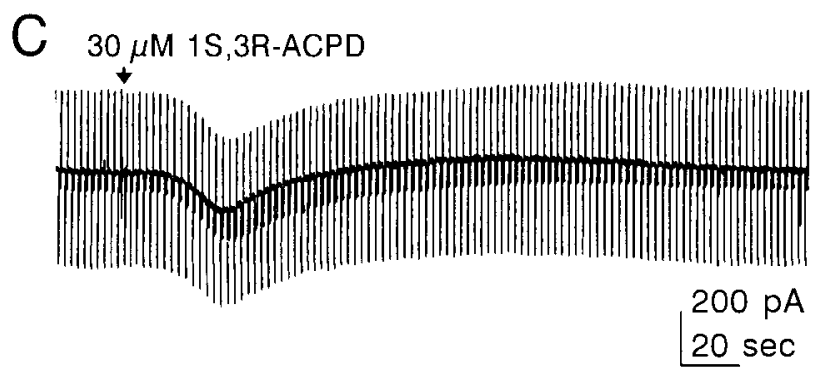

Figure 1. Currents evoked by $1 S, 3 R$-ACPD in DLSN neurons from PTX-treated animals. $A$, In 18 of 19 DLSN "burster" neurons and 24 of 33 "nonburster" neurons, $1 S, 3 R$-ACPD evoked only an inward current accompanied with a conductance increase. This DLSN neuron was held at $-70 \mathrm{mV}$ under single electrode voltage clamp conditions. $B$, In three DLSN neurons, $1 S, 3 R$-ACPD evoked an initial outward current when membrane potentials were held at $-70 \mathrm{mV}$. However, the initial outward current was eliminated when the membrane potential was held at $-80 \mathrm{mV}$. $C$, In seven DLSN neurons, $1 S, 3 R$-ACPD evoked an inward current followed by a long-lasting outward current. This DLSN neuron was held at $-70 \mathrm{mV}$ under single electrode voltage clamp conditions. Membrane conductance was monitored by applying a hyperpolarizing voltage step $(10 \mathrm{mV}, 600 \mathrm{mscc}$ in $A$ and $B ; 10 \mathrm{mV}, 800 \mathrm{msec}$ in $C)$. Each conductance pulse is preceded by a downward capacitative artifact and followed by an upward capacitative artifact.

single electrode voltage-clamp recording techniques were used. Microelectrodes were pulled from filamented capillary glass (standard wall, $1.0 \mathrm{~mm}$ outer diameter, Sutter Instrument Co.) on a Flaming Brown Micropipette Puller (Model P-80/PC) to a final tip resistance of 50-80 $\mathrm{M} \Omega$ (filled with 2 M potassium chloride). An Axoclamp 2A (Axon Instruments) amplifier was used under bridge mode for standard currentclamp recording. Single electrode voltage clamp was achieved under discontinuous mode with an Axoclamp $2 \mathrm{~A}$ amplifier at a sampling rate of $2.5-5 \mathrm{kHz}$. The gain was set at $0.8 \mathrm{nA} / \mathrm{mV}$ ( $30 \%$ duty cycle), time constant at $20 \mathrm{msec}$. The headstage voltage was continuously monitored with an additional oscilloscope to assure the correct operation of the clamp amplifier.

Voltage and current signals were recorded on video tape with a Vetter 4-channel VCR for archiving, and recorded simultaneously on a 2-channel Gould Model 220 chart recorder. Digitized signals were collected on line by means of pcLAMP software and Axoclamp Labmaster hardware, and stored on the hard disk of an AT-clone computer. Digitized raw data can be analyzed off line, and the analyzed data also stored on the hard disk.
Table 1. Currents observed in different subpopulations of PTXtreated DISN neurons

\begin{tabular}{|c|c|c|c|}
\hline \multirow[b]{2}{*}{ Currents observed } & \multicolumn{2}{|c|}{ "Non-burster" } & \multirow{2}{*}{$\frac{\text { "Burster" }}{\text { Type III }}$} \\
\hline & Type I & Type II & \\
\hline \multicolumn{4}{|c|}{ Inward currents with conductance increases } \\
\hline $\mathrm{Q}_{\mathrm{m}}$ current & $4 / 7$ & $13 / 26$ & $1 / 19$ \\
\hline ACPD current & $6 / 7$ & $20 / 26$ & $19 / 19$ \\
\hline \multicolumn{4}{|c|}{ Inward currents with conductance decreases } \\
\hline & $2 / 7$ & $1 / 26$ & $3 / 19$ \\
\hline \multicolumn{4}{|c|}{ Outward currents with conductance increases } \\
\hline Fast & $1 / 7$ & $2 / 26$ & $0 / 19$ \\
\hline Slow & $1 / 7$ & $5 / 26$ & $1 / 19$ \\
\hline
\end{tabular}

Type I is defined as neurons in which a prominent AHP was observed after a single action potential, Type II neuron is defined as neurons in which neither a AHP nor an SADP was observed after a single action potential, and Type III neuron is defined as neurons in which a prominent sADP was observed after a single action potential.

Drug application. Agonists for metabotropic glutamate receptors were applied by microdrop application with a volumetric Eppendorf micropipette into an inlet chamber that is remote from the recording site and brain slice. Bath concentrations of the agonists were then estimated by a dilution factor $(1: 100)$ determined by the volume applied $(10 \mu \mathrm{l})$ into the total bath volume $(1 \mathrm{ml})$. To insure equilibrium conditions, antagonists were superfused for a minimum of 10 min prior to testing of an agonist. Quisqualate, ibotenate, and 6-cyano-7-nitroquinoxaline-2,3dione (CNQX) were purchased from RBI, Natick, MA. Kynurenic acid was purchased from Sigma, St. Louis, MO. The remaining drugs were purchased from Tocris Neuramin, Bristol, UK. All experiments were conducted in the presence of D-AP5 $(50 \mu \mathrm{M})$, CNQX (10-20 $\mu \mathrm{M})$, and bicuculline $(25 \mu \mathrm{M})$.

\section{Results}

\section{PTX-resistant $A C P D$-evoked currents}

ACPD-induced membrane potential changes or currents were studied in pertussis toxin-pretreated animals $(n=78)$. Of these 78 DLSN neurons, 52 were recorded under voltage-clamp conditions. In 43 of 52 DLSN neurons, only an inward current with conductance increase was observed when $1 S, 3 R$-ACPD was applied (Fig. 1 $A$ ). An initial "fast" outward current was observed in 3 of 52 DLSN neurons. As in normal rats, the initial outward current disappeared when the neurons were held at $-80 \mathrm{mV}$ instead of $-70 \mathrm{mV}$ (Fig. $1 B$ ). On the other hand, $1 S, 3 R$-ACPD evoked an initial inward current followed by a prolonged "slow" outward current in 6 of 52 DLSN neurons (Fig. 1C). In the remaining DLSN neuron from this group of $52,1 S, 3 R$-ACPD evoked a triphasic response. Both the "fast" and "slow" outward currents were not further characterized pharmacologically because they were only observed rarely.

In addition to the inward currents accompanied by a conductance increase, $1 S, 3 R$-ACPD, at higher concentrations, also induced an inward current accompanied by a conductance decrease in 5 of 52 DLSN neurons (Fig. $2 A$ ). When the extracellular sodium was reduced to $25 \mathrm{~mm}(n=3)$, a part of the inward current accompanied by a conductance decrease was unmasked in 1 DLSN neuron (Fig. $2 B$ ). The extrapolated reversal potential of this current was at $-90 \mathrm{mV}$, suggesting that this current was due to closure of some potassium channels. This inward current accompanied with a conductance decrease was not further studied because it was always masked by the inward current accompanied by a conductance increase. An inward current accompanied by a conductance decrease was also induced by QA ( $n$ $=2$ ). However, IBO, $1 S, 3 S$-ACPD and L-CCG-I failed to ac- 
A

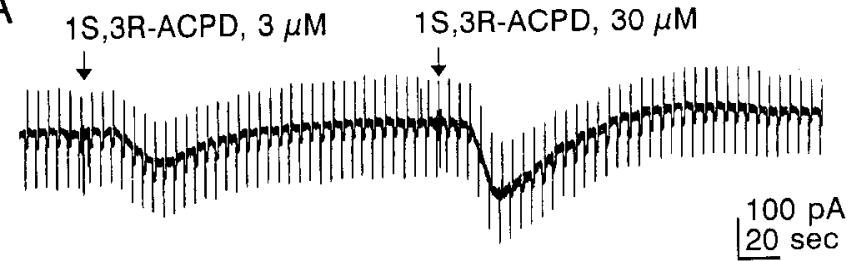

B
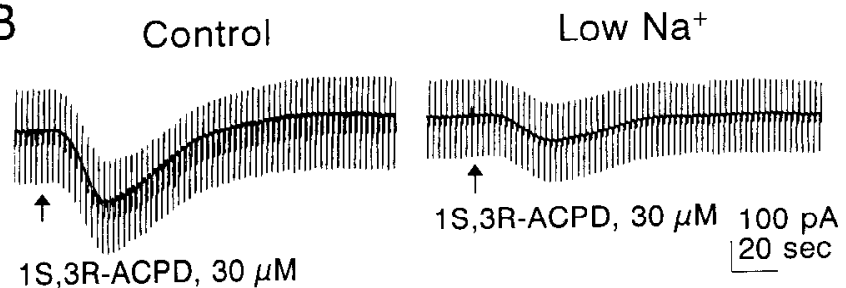

Figure 2. ACPD-evoked inward currents with a conductance decrease in PTX-treated rats. $A$, In a DLSN neuron, $1 S, 3 R$-ACPD evoked an inward current with a conductance increase at $3 \mu \mathrm{M}$. However, it evoked an inward current with a conductance decrease at $30 \mu \mathrm{M}$. Membrane potential was held at $-70 \mathrm{mV}$. Membrane conductance was monitored by applying a hyperpolarizing voltage step $(5 \mathrm{mV}, 1 \mathrm{sec}) . B$, In a DLSN neuron, $1 S, 3 R$-ACPD evoked an inward current accompanied with a conductance increase. However, an inward current accompanied with a conductance decrease was revealed when the extracellular sodium was reduced. Membrane conductance was monitored by applying a hyperpolarizing voltage step $(5 \mathrm{mV}, 800 \mathrm{msec})$.

tivate this inward current at concentrations up to $30 \mu \mathrm{M}$ in the same DLSN neurons in which this current was activated by $1 S, 3 R$-ACPD at $30 \mu \mathrm{m}$. These observations suggest that this current is unlikely to be mediated by mGluR 1 or mGluR 5 .

\section{Two pharmacologically distinct inward currents with a conductance increase}

We studied the pharmacology of inward currents accompanied by a conductance increase evoked by mGluR agonists in DLSN neurons recorded from PTX-pretreated rats $(n=52)$. All experiments were conducted in the presence of ionotropic glutamate receptor antagonists CNQX (10-20 $\mu \mathrm{M})$ and D-2-amino5-phosphonopentanoic acid (D-AP5) $(50 \mu \mathrm{M})$.

DLSN neurons can be classified into three subtypes, based upon their intrinsic membrane properties and their firing patterns (Gallagher et al., 1994b). In brief, type I neurons are defincd as ncurons in which a prominent afterhyperpolarizing potential (AHP) was observed after a single action potential; type II neurons are defined as neurons in which neither an AHP nor a slow afterdepolarizing potential (sADP) was observed after a single action potential; type III neurons are defined as neurons in which a prominent SADP was observed after a single action potential. Type III neurons have also been named "burster" neurons after their characteristic spontaneous burst firing; while type I and II neurons were characterized as "nonburster" neurons.

In 18 of 19 DLSN "burster" neurons (type III), $1 S, 3 R$-ACPD evoked a concentration-dependent inward current, which was accompanied by a conductance increase (Fig. $3 A, B$ ). IBO, QA, and $1 S, 3 S$-ACPD also evoked similar inward currents in these DLSN "burster" neurons (Fig. 4). However, $1 S, 3 R$-ACPD was the most potent agonist. Glutamate at 100 or $200 \mu \mathrm{M}$ failed to evoke any current; at $1 \mathrm{~mm}$, glutamate evoked a small inward current.
A

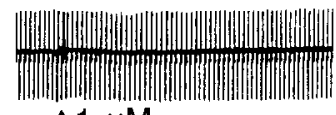

$$
\triangle 1 \mu \mathrm{M}
$$
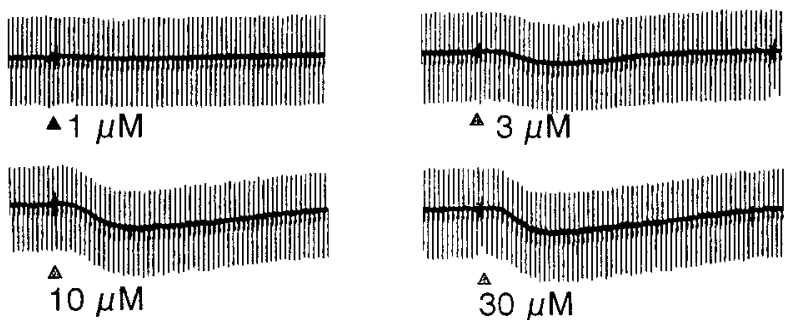

$\triangle 3 \mu \mathrm{M}$
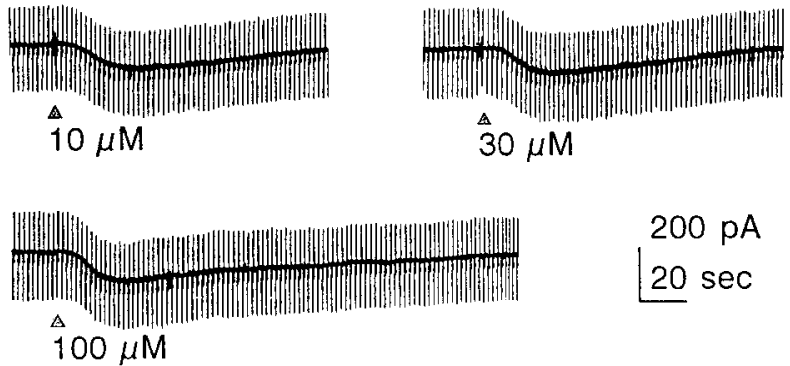

$200 \mathrm{pA}$

$20 \mathrm{sec}$

$100 \mu \mathrm{M}$

\section{B}

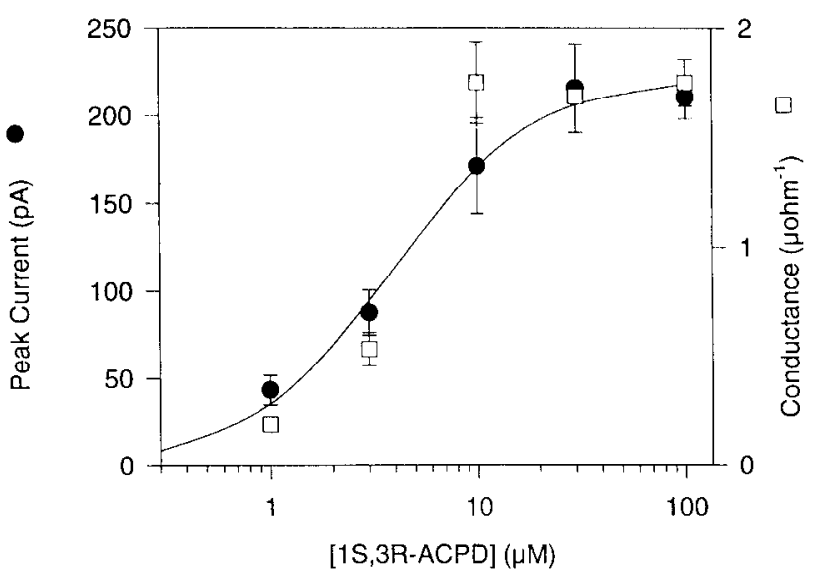

Figure 3. 1S,3R-ACPD evoked an inward current in a concentrationdependent manner in DLSN "buster" neurons. $A$, An inward current was detected with as low as $1 \mu \mathrm{M}$ of $1 S, 3 R$-ACPD in a DLSN "burster" neuron recorded from a PTX-treated rat. The current evoked by $3 \mu \mathrm{M}$ $1 S, 3 R$-ACPD was approximately half of the maximal inward current, which was observed when $30 \mu \mathrm{M} 1 S, 3 R$-ACPD was applied. Membrane potential was held at $-70 \mathrm{mV}$ under single electrode voltage clamp conditions and membrane conductance was monitored by applying a hyperpolarizing voltage step $(10 \mathrm{mV}, 600 \mathrm{msec})$. $B$, Concentrationresponse curve of $1 S, 3 R-\mathrm{ACPD}(n=6)$. All data were collected in DLSN "buster" neurons from PTX-treated rats. The peak of agonist-evoked currents was measured. The maximal current evoked by $1 S, 3 R$-ACPD in a given neuron was then used to normalize all data in that neuron. Data from different neurons were then pooled and presented as mean \pm SEM. These averaged data were fit with a sigmoidal model using Sigma Plot curve-fitting software.

We have demonstrated that L-AP4 $(100 \mu \mathrm{M})$ blocked the ACPD-induced depolarization (Zheng and Gallagher, 1992). We now examined the effects of L-AP4 on inward currents evoked by different mGluR agonists. In DLSN "burster" neurons, L-AP4 caused a small inward current by itself, suggesting that it was a partial agonist (Fig. 5A). However, inward currents evoked by all mGluR agonists, that is, $10 \mu \mathrm{M} 1 S, 3 R$-ACPD, $30 \mu \mathrm{M} \mathrm{IBO}$, $30 \mu \mathrm{M}$ QA, were significantly reduced by $100 \mu \mathrm{M} \mathrm{L}-\mathrm{AP} 4$ to 41.4 $\pm 4.9 \%(n=5, p<0.05), 52.3 \pm 5.6 \%(n=4, p<0.05)$, or $59.0 \pm 3.4 \%(n=3, p<0.05)$ of control currents, respectively (Fig. 5B).

In 17 of 33 "nonburster" DLSN neurons, QA evoked currents were different from those evoked by $1 S, 3 R$-ACPD, IBO, or 1S,3S-ACPD (Fig. 6). In 12 "nonburster" neurons, QA evoked a fast transient inward current followed by a slower and smaller 

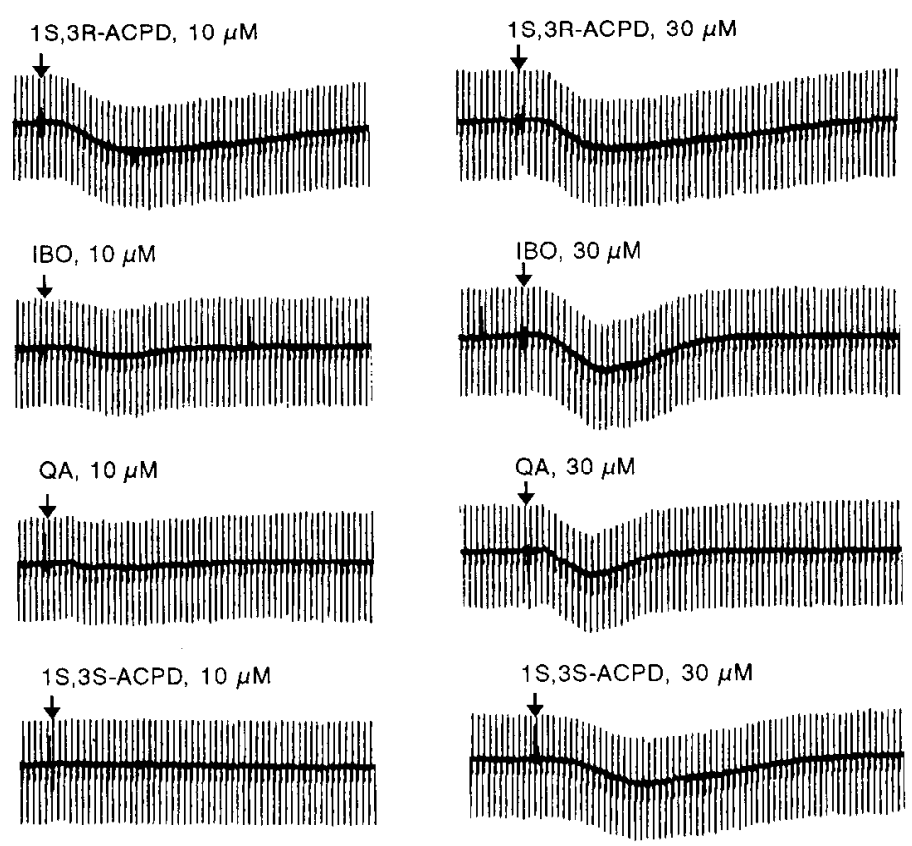

$200 \mathrm{pA}$

$20 \mathrm{sec}$

Figure 4. Inward currents evoked by mGluR agonists in a "burster" neuron. A series of concentrations $(0.3,1,3,10,30,100 \mu \mathrm{M})$ of different agonists were applied to determine their rank order of potency. Currents evoked by $10 \mu \mathrm{M}$ and $30 \mu \mathrm{M} 1 S, 3 R$-ACPD, IBO, QA, and $1 S, 3 S$-ACPD were depicted to illustrate the difference in efficacy of these agonists. Membrane potential was held at $-70 \mathrm{mV}$. Membrane conductance was monitored by applying a hyperpolarizing voltage step $(10 \mathrm{mV}, 600$ $\mathrm{msec})$.

inward current. In five "nonburster" neurons, QA evoked a triphasic response, that is, an initial fast inward current, followed by an outward current superimposed on a slower inward current (Fig. $6 \mathrm{~A}$ ). At the same concentrations, IBO evoked a greater inward current than $1 S, 3 S$-ACPD (Fig. $6 B$ ). Glutamate (100$1000 \mu \mathrm{M})$ cvoked similar currents as $\mathrm{Q} \Lambda(n-5$, data not shown). Thus, in "nonburster" DLSN neurons, QA and glutamate evoked a fast inward current that was absent in most DLSN "burster" neurons. The conductance change associated with the fast inward current could not be measured accurately because there is significant conductance change even during a single voltage step $(600-800 \mathrm{msec})$ which is used to monitor the apparent membrane conductance.

In DLSN "nonburster" neurons, the fast inward current evoked by QA was not blocked by L-AP4, while the slower inward current evoked by QA and the inward current evoked by $1 S, 3 R$ ACPD were blocked by L-AP4 (Fig. 7A). Like in DLSN "burster" neurons, L-AP4 $(100 \mu \mathrm{M})$ also caused a small inward current by itself. In the presence of $100 \mu \mathrm{M} \mathrm{L-AP4}$, the fast inward currents evoked by $10 \mu \mathrm{M}$ QA was $107.9 \pm 19.1 \%$ of control values $(n=4, p>0.05)$, while the inward currents evoked by $30 \mu \mathrm{M} 1 S, 3 R$-ACPD were significantly reduced to $41.8 \pm 5.9 \%$ of control values $(n=3, p<0.05)$. On the other hand, L-AA $\beta \mathrm{H}$ $(200 \mu \mathrm{M})$ selectively blocked the fast inward current evoked by QA, but failed to reduce significantly the slow inward current evoked by QA or $1 S, 3 R$-ACPD (Fig. $7 B$ ). In the presence of $200 \mu \mathrm{M} \mathrm{L}-\mathrm{AA} \beta \mathrm{H}$, the fast inward currents evoked by $10 \mu \mathrm{M}$ QA were significantly reduced to $41.2 \pm 5.3 \%$ of control values $(n$
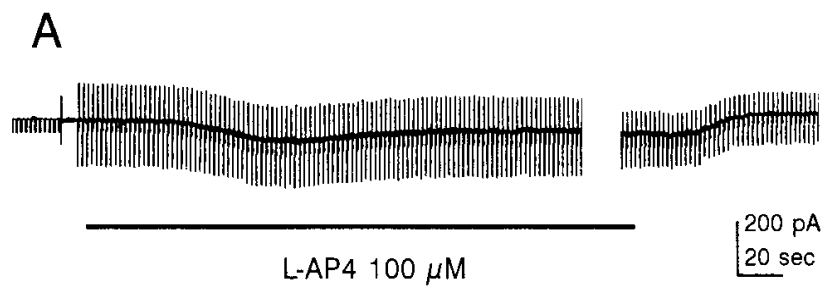

B control
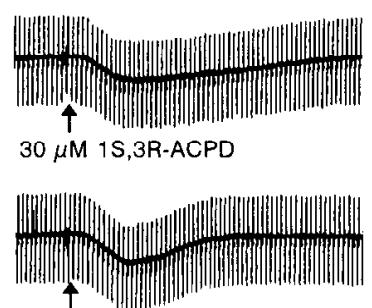

$30 \mu \mathrm{M}$ IBO

$30 \mu \mathrm{M} \mathrm{QA}$

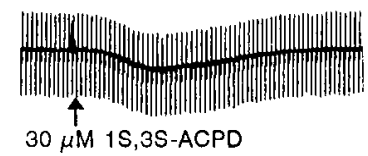

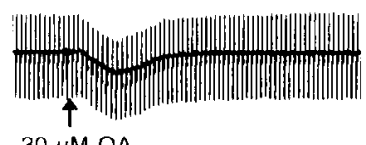
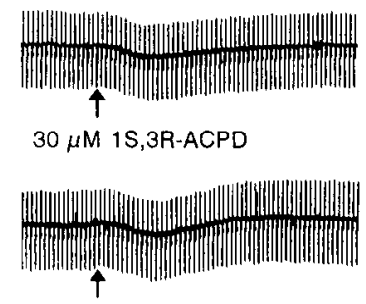

$30 \mu \mathrm{M}$ IBO

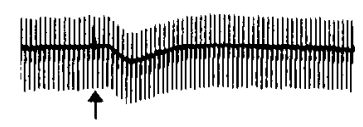

$30 \mu \mathrm{M}$ QA

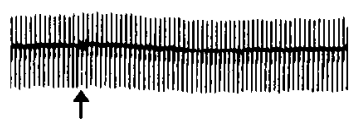

$30 \mu \mathrm{M}$ 1S,3S-ACPD $200 \mathrm{pA}$ $20 \mathrm{sec}$
$100 \mu \mathrm{M}$ L-AP4

Figure 5. L-AP4 blocked the currents evoked by all $m$ GluR agonists in a "burster" neuron. $A$, Superfusion of $100 \mu \mathrm{M}$ L-AP4 evoked an inward current by itself. $B$, The inward current evoked by $1 S, 3 R$-ACPD, IBO, $\mathrm{QA}$, and $1 S, 3 S$-ACPD were all reduced during superfusion of 100 $\mu \mathrm{M}$ L-AP4. The membrane potential was held at $-70 \mathrm{mV}$ and membrane conductance was monitored by applying a hyperpolarizing voltage step $(10 \mathrm{mV}, 600 \mathrm{msec})$.

$=4, p<0.05$ ), while the inward currents evoked by $10 \mu \mathrm{M}$ $1 S, 3 R$-ACPD were $103.5 \pm 11.3 \%$ of control values $(n=5, p$ $>0.05$ ). These observations suggest that there are at least two pharmacologically distinct receptors in some DLSN "nonburster" neurons. Based on their preference to agonists, the ACPDpreferring inward current accompanied with a conductance increase was named the ACPD current. This current was observed in both "burster" and "nonburster" DLSN neurons. The quisqualate-preferring fast inward current in the presence of ionotropic glutamate receptor antagonists was then named metabotropic QA current $\left(\mathrm{Q}_{\mathrm{m}}\right.$ current).

Effects of additional putative mGluR antagonists on the ACPD and $Q_{m}$ currents

We further tested various putative metabotropic glutamate receptor antagonists on the ACPD and $\mathrm{Q}_{\mathrm{m}}$ currents. We have demonstrated that L-AP3 $(50 \mu \mathrm{M})$ blocked the membrane depolarization and long-lasting enhancement of EPSP amplitude induced by $1 S, 3 R$-ACPD (Zheng and Gallagher, 1992). We are particularly interested in which current is sensitive to L-AP3. The ACPD current is not blocked by L-AP3, as depicted in Fig. 8 . In the presence of 50-100 $\mu \mathrm{M} \mathrm{L-AP3}(n=3)$, the ACPD currents evoked by 3 or $10 \mu \mathrm{M} 1 S, 3 R$-ACPD are $90.0 \pm 10.9 \%$, $96.7 \pm 8.0 \%$ of control values, respectively $(n=3)$. L-AP3 (50 

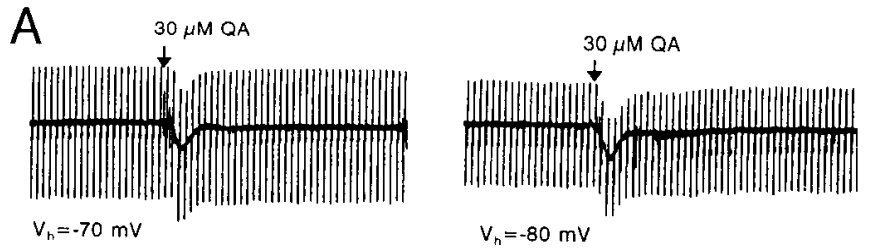

$$
\mathrm{V}_{\mathrm{h}}=-80 \mathrm{mV}
$$

$200 \mathrm{pA}$
$20 \mathrm{sec}$
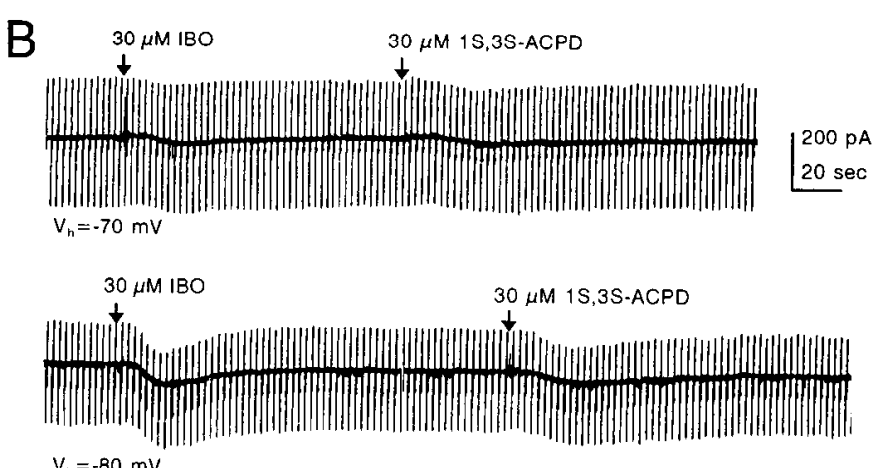

$V_{\mathrm{h}}=-80 \mathrm{mV}$

Figure 6. QA evoked a fast inward current in "nonburster" DLSN neurons. $A$, The currents cvoked by QA in a "nonburster" ncuron werc different from the currents evoked by $1 S, 3 R$-ACPD, IBO, and $1 S, 3 S$ ACPD. $B$, In "nonburster" DLSN neurons, IBO and IS,3S-ACPD evoked currents similar to those evoked by $1 S, 3 R$-ACPD. Membrane conductance was monitored by applying a hyperpolarizing voltage $\operatorname{step}(10 \mathrm{mV}$, $600 \mathrm{msec})$.

$\mu \mathrm{M})$ also failed to block the L-AA $\beta \mathrm{H}$-sensitive $\mathrm{Q}_{\mathrm{m}}$ current as depicted in Fig. $9 A$. In the presence of $50 \mu \mathrm{M} \mathrm{L}-\mathrm{AP} 3$, the fast inward currents evoked by 3 or $10 \mu \mathrm{M}$ QA are $110 \pm 10 \%, 99.2$ $\pm 2.5 \%$ of control values, respectively $(n=2)$. On the other hand, a putative mGluR1 antagonist, $(+)-\mathrm{MCPG}$, also blocked this $Q_{m}$ current as depicted in Fig. $9 B$. In the presence of 200 $\mu \mathrm{M}(+)$-MCPG, the $\mathrm{Q}_{\mathrm{m}}$ current evoked by $10 \mu_{\mathrm{M}} \mathrm{QA}$ is reduced to $23.4 \pm 8.4 \%$ of the control values $(n=3, p<0.05)$. Even after a washout period up to $2 \mathrm{hr}$, there is no apparent recovery of the $\mathrm{Q}_{\mathrm{m}}$ current (data not shown). Thus, the blockade of this current by (+)-MCPG seems to be irreversible. (+)-MCPG (200$500 \mu \mathrm{M}$ ), however, did not block the ACPD current (data not shown).

\section{Discussion}

Two pharmacologically distinct inward currents, that is, the ACPD current and $Q_{m}$ current, have been characterized in DLSN neurons from PTX-treated rats (Table 2). The $\mathrm{Q}_{\mathrm{m}}$ current is differentiated from the ACPD current by the time course of the respective responses and their pharmacology. The $Q_{m}$ current is blocked by L-AA $\beta \mathrm{H}$ and (+)-MCPG, while the ACPD current is resistant to both drugs.
A
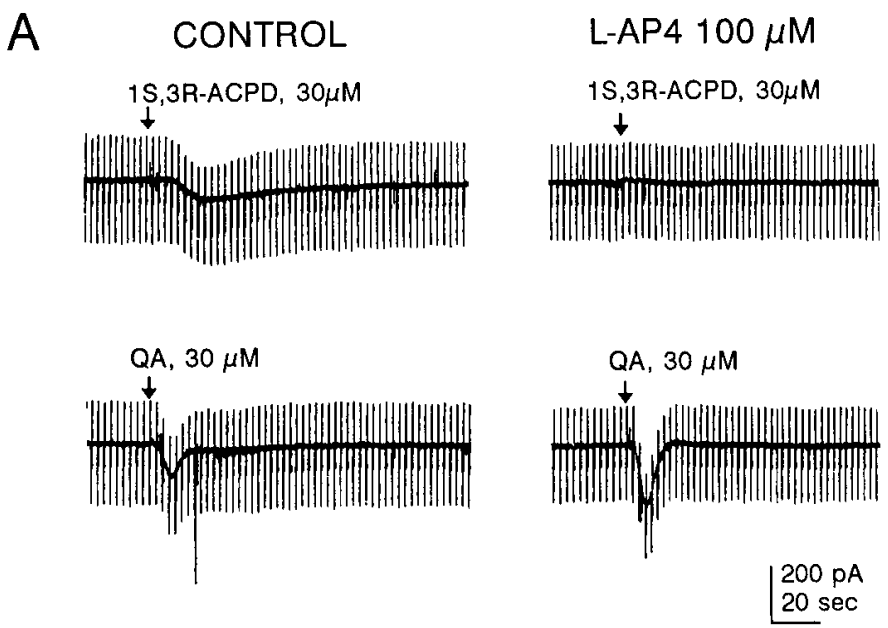

B
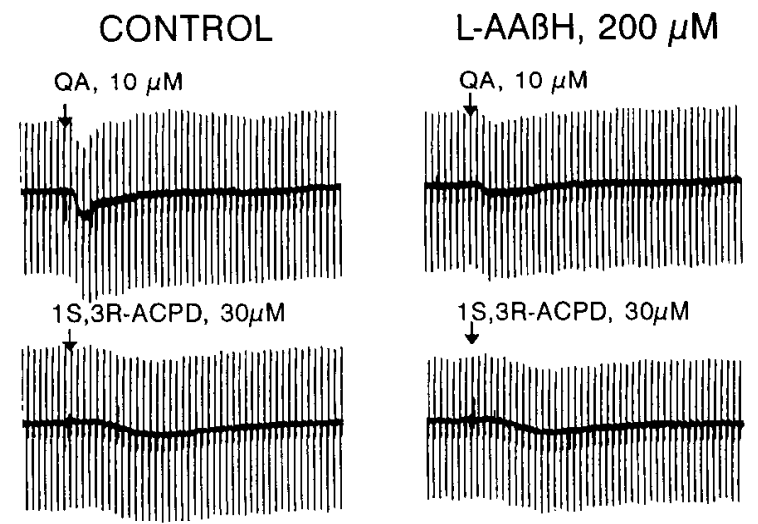

Figure 7. QA-evoked fast inward current was selectively blocked by $\mathrm{L}-\mathrm{AA} \beta \mathrm{H}$ in a "nonburster" neuron. $A$, L-AP4 blocked the $1 S, 3 R$-ACPD evoked current, but not QA-evoked fast inward current in a "nonburster" DLSN neuron. However, the slow inward current evoked by QA was blocked by L-AP4. The membranc potential was held at $-80 \mathrm{mV}$ and membrane conductance was monitored by applying a hyperpolarizing voltage step $(10 \mathrm{mV}, 600 \mathrm{msec})$. $B$, L-AA $\beta \mathrm{H}$ blocked the QAevoked fast inward current, but did not block the slower inward current evoked by QA and $1 S, 3 R-\mathrm{ACPD}$. The membrane potential was held at $-70 \mathrm{mV}$ and membrane conductance was monitored by applying a hyperpolarizing voltage step $(10 \mathrm{mV}, 600 \mathrm{msec})$.

These two inward currents distribute differentially within subpopulations of DLSN neurons recorded from PTX-treated rats. DLSN neurons can be classified into three major types, based upon their intrinsic membrane properties and their firing patterns (Gallagher et al., 1994b). The most prevalent current is the ACPD current, which can be recorded in all three cell types, while the $\mathrm{Q}_{\mathrm{m}}$ current is observed primarily in type I and type II DLSN neurons (Table 1). The distribution of these currents in normal rats may be different. Since all these agonists evoked

Table 2. Pharmacological properties of two identified inward currents in PTX-treated DISN neurons

\begin{tabular}{llllll} 
& & \multicolumn{3}{c}{ Antagonist sensitivity } \\
\cline { 3 - 6 } $\begin{array}{l}\text { Cur- } \\
\text { rents }\end{array}$ & Rank order of agonist potency & L-AP4 & L-AP3 & L-AA $\beta$ H & $\stackrel{\text { MCPG }}{ }$ \\
\hline $\mathrm{Q}_{\mathrm{m}}$ & $\mathrm{QA}>$ Glu & no & no & yes & yes \\
ACPD & $1 S, 3 R$-ACPD $>$ L-CCG-I $=$ IBO $>1 S, 3 S$-ACPD & yes & no & no & no \\
\hline
\end{tabular}




\section{Control}

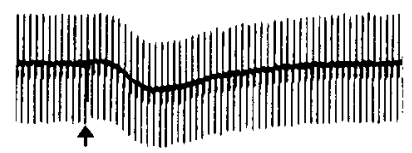

$10 \mu \mathrm{M} 1 \mathrm{~S}, 3 \mathrm{R}-\mathrm{ACPD}$

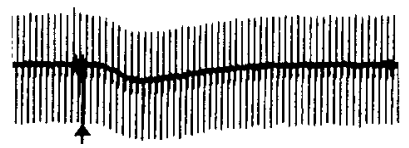

$10 \mu \mathrm{M} Q \mathrm{~A}$

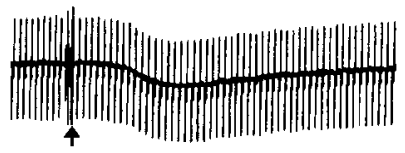

$30 \mu \mathrm{M}$ 1S,3S-ACPD
$50 \mu \mathrm{M}$ L-AP3

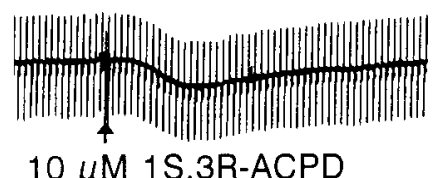

$10 \mu \mathrm{M}$ 1S,3R-ACPD
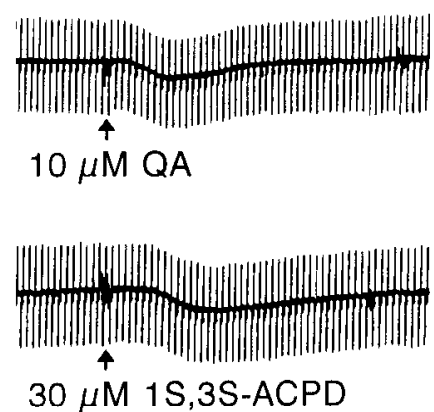

$200 \mathrm{pA}$

$15 \mathrm{sec}$

Figure 8. L-AP3 failed to block the ACPD current. All traces were collected in the same DLSN "nonburster" neuron. Membrane potential was held at $-70 \mathrm{mV}$ under single electrode voltage clamp conditions, and membrane conductance was monitored by applying a hyperpolarizing voltage step $(5 \mathrm{mV}, 800 \mathrm{msec})$.

burst firing in normal rats, it is very difficult to isolate these inward currents from the voltage-gated currents related to the burst firing. PTX-treatment itself may have some effects on the intrinsic properties of DLSN neurons. For instance, type III neurons usually comprise about $15 \%$ of the total population of DLSN neurons ( 8 of 52) in normal rats; whereas in PTX-treated rats, $35 \%$ of DLSN neurons (27 of 78) are type III neurons.

QA evoked a fast inward current $\left(Q_{m}\right.$ current) in approximately $50 \%$ of DLSN "nonburster" neurons from PTX-treated rats. Since the $Q_{m}$ current has a rather fast time course, we initially suspected that this current may be mediated by an inotropic receptor. However, further experiments suggested that this current is not mediated by ionotropic glutamate receptors. Inward currents evoked by AMPA (10-30 $\mu \mathrm{M})$ have a time course clearly slower than the $Q_{m}$ current and similar to the ACPD current. Currents evoked by AMPA (10-30 $\mu \mathrm{M})$ are completely blocked by CNQX (10-20 $\mu \mathrm{M}$ ) or kynurenate (3 $\mathrm{mm}$ ). On the other hand, the $Q_{m}$ current persists in the presence of CNQX or kynurenate. Furthermore, the $Q_{m}$ current is blocked by $\mathrm{L}-\mathrm{AA} \beta \mathrm{H}$ and $(+)-\mathrm{MCPG}$, which are reported as antagonists at metabotropic receptors, and are inactive at ionotropic glutamate receptors (Ormandy, 1992; Porter et al., 1992; Eaton et al., 1993; Jane et al., 1993). Thus, this QA-preferring current is mediated by a metabotropic glutamate receptor. Since we are measuring only the peak of QA-evoked currents, and since some DLSN neurons, in the presence of the ionotropic glutamate receptor antagonists, show a rather significant slow inward current following application of QA at higher concentrations (> $30 \mu \mathrm{M}$ ), part of the peak current in these neurons may be due to activation of an AMPA receptor, or a non-AMPA, nonNMDA ionotropic receptor, that is, the ACPD current.

The rank order of agonist potency for the $Q_{m}$ current is not fully determined because $1 S, 3 R$-ACPD, L-CCG-I, and IBO also activate the ACPD current, which always coexists with the $Q_{m}$

A

Control

$50 \mu \mathrm{M} \mathrm{L-AP3}$
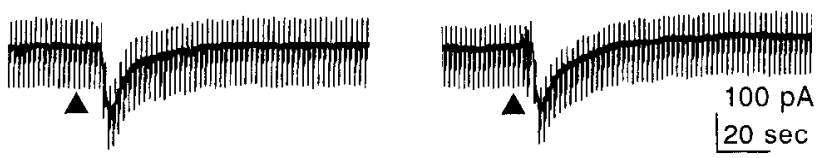

B
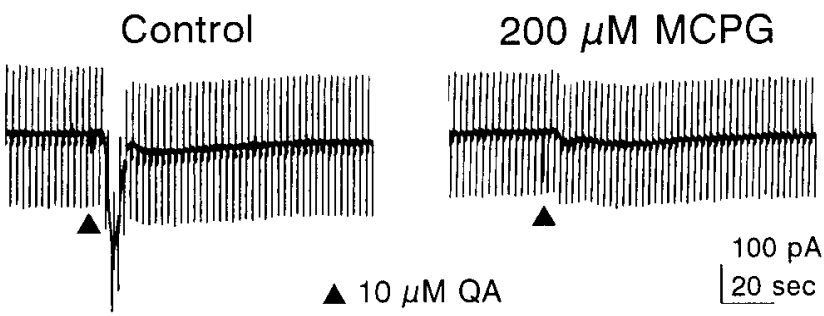

Figure 9. The $\mathrm{Q}_{\mathrm{m}}$ current was blocked by (+)-MCPG, but was not blocked by L-AP3. $A$, In this DLSN neuron, superfusion of $50 \mu \mathrm{M} \mathrm{L-AP3}$ failed to reduce the inward current-evoked by $\mathrm{QA}$. However, in the same DLSN neuron, $200 \mu \mathrm{M}$ L-AA $\beta \mathrm{H}$ blocked the fast inward current evoked by $Q A$, that is, $Q_{m}$ current (data not shown). Membrane potential was held at $-70 \mathrm{mV}$ under single electrode voltage clamp conditions, and membrane conductance was monitored by applying a hyperpolarizing voltage step $(10 \mathrm{mV}, 800 \mathrm{msec}) . B$. In this DLSN neuron, superfusion of $200 \mu \mathrm{M}(+)$-MCPG selectively blocked the fast inward current evoked by QA, but did not reduce the slow inward current evoked by QA or $1 S, 3 R$-ACPD (data not shown). Membrane potential was held at $-70 \mathrm{mV}$ under single electrode voltage clamp conditions, and membrane conductance was monitored by applying a hyperpolarizing voltage step $(10 \mathrm{mV}, 800 \mathrm{msec}$ under the control conditions; $5 \mathrm{mV}, 800 \mathrm{msec}$ in the presence of $(+)-\mathrm{MCPG})$.

current. However, glutamate is a rather potent agonist for the $Q_{m}$ current. Messenger RNAs for mGluR1 and mGluR5 have been reported to be abundant in the rat DLSN (Shigemoto et al., 1992, 1993). Our biochemical study (Zheng et al., 1994) demonstrated that $1 S, 3 R$-ACPD increased IP3 levels in rat DLSN slices, suggesting the existence of a PLC-coupled mGluR. At concentrations higher than $100 \mu \mathrm{M}, 1 S, 3 R$-ACPD also induced a biphasic response, that is, a fast inward current followed by a slower inward current (unpublished observation, Zheng and Gallagher). Thus, the $Q_{m}$ current is likely mediated by mGluR1 or mGluR5, which prefer QA and glutamate (Schoepp and Conn, 1993).

We have attempted to differentiate mGluR 1 and mGluR5 by their sensitivity to PTX. This $\mathrm{Q}_{\mathrm{m}}$ current persists in PTX-treated rats and, therefore, may be mediated by mGluR5, which is resistant to PTX (Abe et al., 1992). However, our preliminary observations suggest that the $Q_{m}$ current is observed in a higher percentage of DLSN neurons recorded from normal rats. Therefore, the receptor mediating this current may be partially sensitive to PTX. Furthermore, the three alternative splicing products of mGluR I have different PTX sensitivity. The mGluR $1 \alpha$ and mGluRlc are PTX sensitive (Pin et al., 1992; Tanabe et al., 1992), while the mGluR $1 \beta$ is not (Pickering et al., 1993). Presently, it is impossible to differentiate mGluR 1 and mGluR5 at rat DLSN neurons based upon PTX sensitivity.

In addition to the ACPD current and $Q_{m}$ current, an IBOpreferring inward current is observed in a small number of DLSN neurons. In these DLSN neurons, the rank order of agonist potency was IBO $>$ L-CCG-I $>1 S, 3 S$-ACPD $>1 S, 3 R$ ACPD $>$ QA. Since this current frequently coexists with the ACPD current, it is difficult to characterize pharmacologically. However, this IBO-preferring current is not mediated by NMDA 
receptors because, in the presence of the ionotropic glutamate receptor antagonists, $100 \mu \mathrm{M}$ NMDA failed to evoked any inward current. Furthermore, this IBO-preferring current is blocked by $(+)-M C P G(200 \mu \mathrm{M})$. Thus, this IBU-preferring current is likely mediated by a metabotropic receptor.

The ACPD current persists in neurons injected with GTP $\gamma \mathrm{S}$ and shows no dependency on temperature; it, therefore, is likely mediated by an ionotropic receptor (Zheng, Hasuo, and Gallagher, unpublished observation). This current is insensitive to CNQX and D-AP5, and prefers 'mGluR agonists,' such as $1 S, 3 R$ ACPD and $(2 S, 3 S, 4 S)$ - $\alpha$-(carboxyclopropyl)-glycine (L-CCGI). Thus, the ACPD current is not mediated by the three wellknown ionotropic glutamate receptors, that is, NMDA, AMPA, or KA receptors.

We have used L-AP3 $(50 \mu \mathrm{M})$ and L-AP4 (100-200 $\mu \mathrm{M})$ as antagonists of mGluRs to study the role of metabotropic glutamate receptors in the induction of LTP (Zheng and Gallagher, 1992); therefore, it is of great interest for us to examine which of these receptors is blocked by L-AP3 or L-AP4 at the same concentration range. L-AP3 failed to block the $\mathrm{Q}_{m}$ current, a response mediated by $\mathrm{mGluR} 1$ or mGluR5. This observation is in agreement with data from cloned receptors expressed in Chinese hamster ovary cells (Aramori and Nakanishi, 1992) and bahy hamster kidney cells (Thomsen et al., 1993). On the other hand, L-AP4 at 100 to $200 \mu \mathrm{M}$ blocks the ACPD current, but fails to block the $Q_{m}$ current. Thus, the blockade of LTP by L-AP3 or L-AP4 is not due to blockade of a PLC-coupled mGluR.

(+)-MCPG has been introduced as a selective and competitive antagonist at mGluR 1 (Bashir et al., 1993, but see Chinestra et al., 1993). It blocks both the $\mathrm{Q}_{\mathrm{m}}$ current and IBO-preferring current in rat DLSN neurons. Ongoing experiments are being conducted to assess the various actions of $(+)-\mathrm{MCPG}$.

In summary, our data demonstrate that multiple subtypes of mGluRs may exist even in one neuron. Selective antagonists are needed to determine the functional roles of these mGluRs. Currently available putative antagonists, such as (+)-MCPG, are not selective, and frequently are also partial agonists.

\section{References}

Abe T, Sugihara H, Nawa H, Shigemoto R, Mizuno N, Nakanishi S (1992) Molecular characterization of a novel metabotropic glutamate receptor mGluR5 coupled to inositol phosphate/ $\mathrm{Ca}^{2+}$ signal transduction. J Biol Chem 267:13361-13368.

Aramori I, Nakanishi S (1992) Signal transduction and pharmacological characteristics of a metabotropic glutamate receptor, mGluR1, in transfected CHO cells. Neuron 8:757-765.

Bashir ZI, Bortolotto ZA, Davies CH, Berretta N, Irving AJ, Seal AJ, Henley JM, Jane DE, Watkins JC, Collingridge GL (1993) Induction of LTP in the hippocampus needs synaptic activation of glutamate metabotropic receptors. Nature 363:347-350.

Cha JH, Makowiec RL, Penney JB, Young AB (1990) L-[3H]glutamate labels the metabotropic excitatory amino acid receptor in rodent brain. Neurosci Lett 113:78-83.

Chinestra P, Aniksztejn L, Diabira D, Ben-Ari Y (1993) (RS)- $\alpha$-methyl-4-carboxyphenylglycine neither prevents induction of LTP nor antagonizes metabotropic glutamate receptors in CA1 hippocampal neurons. J Neurophysiol 70:2684-2689.

Eaton SA, Jane DE, Jones PLSJ, Porter RHP, Pook PC-K, Sunter DC, Udvarhelyi PM, Roberts PJ, Salt TE, Watkins JC (1993) Compet- itive antagonism at metabotropic glutamate receptors by $(S)$-4-carboxyphenylglycine and $(R S)$ - $\alpha$-methyl-4-carboxyphenylglycine. Eur J Pharmacol Mol Pharmacol 244:195-197.

Gallagher JP, Zheng F, Shinnick-Gallagher P (1994a) Long-lasting modulation of synaptic transmission by metabotropic glutamate receptors. In: The metabotropic glutamate receptors (Conn PJ, Patel J, eds), in press. Totowa, NJ: Humana.

Gallagher JP, Zheng F, Hasuo H, Shinnick-Gallagher P (1994b) Neuronal activities of the dorsolateral septal nucleus neurons in vitro. Progr Neurobiol 173-193.

Jane DE, St J Jones PL, Pook PC-K, Salt TE, Sunter DC, Watkins JC (1993) Stereospecific antagonism by $(+)-\alpha$-methyl-4-carboxyphenylglycine (MCPG) of $(1 S, 3 R)$-ACPD-induced effects in neonatal rat motoneurones and rat thalamic neurones. Neuropharmacology 32: $725-727$.

Nakanishi S (1992) Molecular diversity of glutamate receptors and implications for brain function. Science 258:597-603.

Ormandy GC (1992) Inhibition of excitatory amino acid-stimulated phosphoinositide hydrolysis in rat hippocampus by $\mathrm{L}$-aspartate- $\beta$ hydroxamate. Brain Res 572:103-107.

Pickering DS, Thomsen C, Suzdak PD, Fletcher EJ, Robitaille R, Salter MW, MacDonald JF, Huang X-P, Hampson DR (1993) A comparison of two alternatively spliced forms of a metabotropic glutamate receptor coupled to phosphoinositide turnover. J Neurochem 61:8592.

Pin J-P, Waeber C, Prezeau L, Bockaert J, Heinemann SF (1992) Alternative splicing generates metabotropic glutamate receptors inducing different patterns of calcium release in Xenopus oocytes. Proc Natl Acad Sci USA 89:10331-10335.

Porter RHP, Briggs RSJ, Roberts PJ (1992) L-Aspartate- $\beta$-hydroxamate exhibits mixed agonist/antagonist activity at the glutamate metabotropic receptor in rat neonatal cerebrocortical slices. Neurosci Lett 144:87-89.

Schoepp DD, Conn PJ (1993) Metabotropic glutamate receptors in brain function and pathology. Trends Pharmacol Sci 14:13-20.

Shigemoto R, Nakanishi S, Mizuno N (1992) Distribution of the mRNA for a metabotropic glutamate receptor (mGluR1) in the central nervous system: an in situ hybridization study in adult and devcloping rat. J Comp Neurol 322:121-135.

Shigemoto R, Nomura S, Ohishi H, Sugihara H, Nakanishi S, Mizuno $N$ (1993) Immunohistochemical localization of a metabotropic glutamate receptor, mGluR5, in the rat brain. Neurosci Lett 163:53-57.

Stevens DR, Gallagher JP, Shinnick-Gallagher P (1984) Intracellular recordings from rat dorsolateral septal neurons, in vitro. Brain Res 305:353-356.

Tanabe Y, Masu M, Ishii T, Shigemoto R, Nakanishi S (1992) A family of metabotropic glutamate receptors. Neuron 8:169-179.

Thalmann $R$ (1987) Pertussis toxin blocks a late inhibitory postsynaptic potential in hippocampal CA3 neurons. Neurosci Lett 82:4146.

Thomsen C, Mulvihill ER, Haldeman B, Pickering DS, Hampson DR, Suzdak PD (1993) A pharmacological characterization of the mGluR $1 \alpha$ subtype of the metabotropic glutamate receptor expressed in a cloned baby hamster kidney cell line. Brain Res 619:22-28.

Twery MJ, Wong LA, Gallagher JP (1991) Somatostatin-induced hyperpolarization of septal neurons is not blocked by pertussis toxin. Eur J Pharmacol 245:299-301

Zheng F, Gallagher JP (1992) Metabotropic glutamate receptors are required for the induction of long-term potentiation. Neuron 9:163172.

Zheng F, Gallagher JP (1993) Pertussis toxin selectively blocked burst firing induced by $1 S, 3 R$-ACPD at rat dorsolateral septal nucleus neurons. Soc Neurosci Abstr 19:470.

Zheng F, Lonart G, Johnson KM, Gallagher JP (1994) (1S,3R)-1aminocyclopentane-1,3-dicarboxylic acid ( $S, 3 R$-ACPD) induced burst firing via an inositol-1,4,5-triphosphate-independent pathway at rat dorsolateral septal nucleus. Neuropharmacology 33:97-102. 